\title{
Using Tablet on Education
}

\author{
Rateeba Algoufi ${ }^{1, *}$ \\ ${ }^{1}$ Education Department, Northern Illinois University, Dekalb, USA \\ *Correspondence: Education Department, Northern Illinois University, Dekalb, USA. E-mail: ralgoufi@hotmail.com
}

Received: April 3, 2016

Accepted: April 14, $2016 \quad$ Online Published: June 22, 2016

doi:10.5430/wje.v6n3p113

URL: http://dx.doi.org/10.5430/wje.v6n3p113

\begin{abstract}
Technological advancements in digital devices have made educational methodology to adopt new strategies and procedures to suit the Mobile learning era. Mobile devices such as tablets are growing to be the focus of research studies and educational use around the globe in the present day. With the influence of handy computing tablets in the hands of everybody and anybody, the era has come to think about employing tablets for teaching. What category of technology, substance, and tablet device is presently being integrated into education? What are the outcomes in conditions of student learning results? What do the instructors believe? Are the other parties in education content? This paper analyzes information and reflections from numerous executions of employing computing tablets in education to find out and move further. In spite of many excellent anecdotes concerning using tablets in education, tablets after all are technology products that contain a delicate electronic mechanism, require power to function and connectivity for right to use. A lot has been discovered from technology employment in education and enhanced upon. Nevertheless, it is to be noteworthy that entirely realized the possibility of any technology device and its employ in education is entirely reliant upon electrical muscle, system connectivity, and user capability.
\end{abstract}

Keywords: tablet computing; technology devices in education; m-learning; e-learning; m-education

\section{Introduction}

With the fast evolution of present educational methods, technology has a noteworthy influence on schooling and learning procedures. Technology in education plays an important position in all levels of teaching owing to an upsurge in the use of the internet and electronic devices. Tablets provide users with a prospect to study and discover information everywhere and at any time. Therefore, many researchers have studied and investigated the application of tablets for education to expand teaching strategies to meet the 21 st-century student's requirements. Instructors have been investigating the possibility of engaging tablets since the early entrance of this instructional device. Consequently, it is vital to understand the use of tablet equipment in education by reviewing its returns and restrictions through user opinions.

Many researchers have stated that it is the widespread use of mobile technologies that has grown so fast and caused mobile technologies to lead the learning world of today. Over the recent years integration of mobile technology in education has been witnessing a development, which has caused its dominance over other technologies such as personal computers.

\subsection{Definitions}

Literature indicates multiple attempts to define the term "mobile learning" in the relation to usage of mobile tablets for learning purposes. Perhaps, the simplest definition was provided by Jacob, and Issac, (2008), which was based on the direct relation between learning and using mobile devices; they have defined this domain of learning as studying using the assistance of mobile devices (p. 19). Jacob and Issac, (2008) also borrowed other definition of mobile learning from other authors' definitions and used them in their study. For example, they used Clark Quinn's definition which states that mobile learning intersects between the use of mobile devices which are wireless and small computing machines and learning through communication technology which is commonly referred to as e-learning (Jacob, and Issac, 2008).

Another interesting definition was the one which Cheung and Hew, (2009) used in their study and it states that mobile technology is any small device that is easily carried in hand and delivers computing services with capabilities of storing and retrieving information. Portable handheld machinery vary from other mobile machines such as laptops since they 
are characteristically bigger and heavier not to be able to fit in hand (Cheung and Hew, 2009).

Cochrane prefers Laurillard's (2007) definition that emphasizes the teacher's part that mobile learning being the digital backing of adaptive, exploratory, informative, shared, and industrious education deeds in inaccessible locations, offers an extensive diversity of settings in which the instructor can function (Cochrane, 2007: p. 134). The authors tried to define mobile learning were affected by previous efforts of researchers who addressed definitions for e-learning in general. For example, Ruiz, et al., (2006) referred to E-learning as usage of internet methodologies to convey wide-ranging solutions that augment information and presentation. Thus, defining mobile learning became similar in many ways to that of E-learning in general.

\subsection{Statement of the Problem}

Unfortunately, even as information technology improves and advances in teaching, effective use of mobile learning still needs research and evaluation. Mobile tablets are also ICT elements, so why must we still think about using tablets in education and what is its probable influence on the parties involved (Abu-Al-Aish, 2014). This paper offers a literature review of what is available and investigates the openings and subjects in regards to utilizing tablets in education. A majority of the stakeholders in the teaching organizations are by now struggling to convey essential education - what is essential to them and how they should be strengthened if they are to be convinced to use tablet devices in delivering or conveying education. To grasp the notion of tablet use in learning, it is vital to comprehend the mobile education concept. M-learning concerns offering dependent learning where learners are willing to choose at what time, where, and the mechanism of learning that bests suit them. Diverse tools represent mobile learning counting but not restricted to Smartphone's, tablets, and PDAs (Shal, Looi, et al., 2011). These devices can be relevant in some methods to aggravate education in and out of the schoolroom planning. Their manifestation, tablets had been examined and used by teachers to survey their returns to the students or learning environment. A tablet is a portable computing toll bigger than Smartphone's and lesser than a laptop, and it does not need a keyboard or a mouse. Its application is diverse all over the world, and it is more effective than any other mobile device. The use of tablets has enabled people to have the chance to read books, discern knowledge, and even watch films using a single device, a tablet.

\subsection{Statement of Purpose}

This qualitative study intention is to explore the usage of tablets in learning settings and in courses to assess the usefulness of such instructional tools. Obviously, parallel to any learning activity or training opportunity learners bring to the classroom their passion of owning and knowing how to use technology and tablets. In other words, the learning process widens to include the learners' preferences and concerns about integrating tablets and smart technology devices into their learning. Teachers, course designers, sponsors, and educators are concerned about how effective to implement a teaching or training program while making use of the newest tools for the augmentation of education. It is significant to understand how the learner's cognition, behavior, and motivation will be controlled by the by the potential of mobile and tablet learning environments, teaching will be supported, and learning will be facilitated while providing personalized environments of education. (Cochrane, 2010: p. 143). In this review, the research will focus on the effectiveness of employing tablets in teaching and learning in the future.

\subsection{Research Questions}

To examine the application of tablets in education, this literature review seeks to solve the questions below:

- What is the educational justification for employing tablets in education?

- What are the learners and educator's standpoints regarding incorporating tablets into their education and training?

-What is the imminent future of mobile devices and tools in teaching like?

The literature assessment of this study will address each query of the research questions separately to provide a synthesis of the background literature for this paper. However, the chief rationale of this appraisal is to examine what had been done so far on this subject, and the standpoints of such knowledge.

\section{Literature Review}

\subsection{The Pedagogical Rationale for Employing Tablet Learning in Education}

Because of their multi-application and incorporation of interactive media, mobile tablets provide educating opportunities for different learning forums and type of intellect. For visual students, the graphic applicant interface of tablets utilization permits them to develop the multimedia scheme and visualize ideas, for instance by watching videos (Schnackenberg, 2013). Moreover, Tablets do not need the application of a keyboard or a mouse; rather, their usage 
relies on touching the display or the screen and steering by the use of fingertips. According to (Schnackenberg, 2013), tablets do not just function for visual learners, but also impact hearing students, for example in the way a message can be delivered to them. This feature can be accessible to other technologies; however, tablets and other handy technologies have a select component that suits perceptible learners.

Cheung and Hew (2009) conducted a study in which they reviewed empirical articles to summarize the research literature related to devices such as smart phones and tablets in mobile teaching in K-12 and advanced education establishments. They investigated areas such as promises that mobile learning provided a budding forum to transform education, private ownership over teaching responsibilities, and the knowledge used in the provision of learning ( $\mathrm{p}$. 153). They indicated the significance of their study as not only helpful to academics and instructors in recognizing the current research themes, study methodologies, and practice of mobile devices in K-12 and advanced education establishments, but also proposed guidelines for future investigations (p. 155).

Herrington et al. (2009) conducted a project in which they tried to structure the strategy, application and assessment of specific pedagogies for using mobile handheld in advanced learning classes" (Herrington et al. 2009: p. 129). In creating a set of design doctrines for mobile teaching in advanced education, grounded on the knowledge of instructors and students in a Faculty of Education, the researchers were aware that not all ideologies might be pertinent or essential in all tertiary education settings. However, these ideologies can offer valuable strategies for educators, instructional designers and developers as they strategize and improve curriculum resources for students of this century.

Nassoura, (2012) conducted a study in which the purpose of the author was to probe students' reception of m-Learning for advanced learning in Saudi Arabia. Among other things he investigated were the key aspects that influence the use of $\mathrm{m}$ - Learning with attention on higher education learners in Saudi Arabia. The study used a sample of 80 pupils and a qualitative strategy to find the aspects that govern the students' intent to use m-Learning. The outcomes from statistical scrutiny show that the reception level of learners on m-Learning at the highest level.

Nassoura's (2012) examination outcomes established five premises. The results exhibited that an optimistic approach leads to the developmental intent to use m-Learning. Thus, the university management should have an emphasis on the strategy m-Learning structure that is suitable with student's views. Good insight and university strategy were two main aspects that lead to the attainment of high standards through the m-Learning system. (p. 7)

Alzaza and Yaakub, (2011) investigated in their study students' responsiveness and necessities of mobile learning facilities among Malaysian learners in the advanced education setting and established that advanced education setting was prepared for the execution of mobile education. They studied a sample of 261 students (male and female), who were selected randomly and their responses were analyzed statistically showing that $95 \%$ of the students had mobile devices, which they used in the course of their university studies (Alzaza and Yaakub, 2011).

Herrington (2007) claims that a majority of university lecturers who do not experience the comfort in employing technology find it difficult to apply a modern technology tool through information technology. Although a majority of educators presently is sufficiently contented to engage technology, it seems that they cannot contend their students in social media and mobile teaching. Thus, the definition of the application of novel technologies and the association to novel approaches to education could be dissimilar due to generational diversity in the inference of teaching modes (Herrington, 2007). Generational teaching modes need instructors to employ the suitable equipment and teaching mechanism to the learners schooling forms and age groups. Provision mechanisms are the instance of teaching differentiation amid generations. While baby boomers adapted to workshops' and teaching in lecture halls, Millennial have embraced E-learning. The education diversities are within the generation not between them still. Based on these standpoints, many explorers and instructors evaluated the application of tablets in education and discovered similar benefits and disadvantages that are considerable.

Researchers have always explained how the application of tablets suits well with learner's diverse learning styles that motivate them to use more time discovering their learning abilities (Schnackenberg, 2013). Thus, the use of the tablet in education would offer a chance to attract novel students in the education sector. Obviously, students who find attention in the use of technology in learning would profit from the integration and enhance their skills in education.

\subsection{Benefits of Applying Tablets in Education}

Wang, Chen et al. (2009) claim that mobile teaching encompassing tablets produce new possibilities for communication and commanding teaching. Interactive and vigorous learning mechanisms help learners to obtain knowledge as well as increasing the 21 st-century proficiencies (Wang, Chen, et al., 2009). They assist the students to think decisively, solve situations and to make accurate choices. One of the skills in learning is note making and taking. To improve this skill as a segment of active teaching, some computer science teachers established a PC tablet initiated 
strategy to motivate learners sending inquiries and records in working together to solve the allocated situations in the course of the lecture. The educator could see all the learners' solutions and select one or two to demonstrate on the screen, and he could interpret them digitally while describing.

The application of tablet is not restricted only to disburse them amid students to be appropriate independently; it can be pertinent as an electric writing board as well. The use of tablets alters the style of presentation. Rather than using static slides, educators presently can employ multimedia presentations, interpret slides while discussing, and document presentations. Tablets permit drawing, interpreting, and documenting using a variety of colors of ink by the infinite number of pages devoid of the necessity to expunge them. Learners can also review the notes out of the class setting employing a variety of software and not essentially through tablets. The application of tablets in teaching extended from schoolroom to help students consolidate their education. Whether engaging commercial almanacs or utilizing systems such as the Doodle, learner's can keep the trace and the timetable their group schemes and engagements for example (Wang, Chen, et al., 2009).

Practical application of tablets in education represents one kind of the benefits of employing such a device in the learning society. Researchers indicate that tablets can influence the learners schooling and schooling behaviors. Wang et al. (2009) mention a survey analysis carried out in 2005 at a japans college revealing that learners sent an average of 200 email texts utilizing their mobile phones every week. The outcome of this analysis indicates that learners had a possible attention in m-learning in universal. Nevertheless, there was one subject concerning the application of mobile phones regarding the small size of the screens or displays. Tablets appeared as the solution that offers the same advantages as a mobile smartphone with a satisfactory display size. The benefits of applying tablets are restricted to one advance; nevertheless, there are some difficulties with instructors requiring being conscious of when applying the device.

\subsection{Challenges of Applying the Tablets in Learning}

According to Herrington and Herrington (2007), the widespread availability of devices and tablets have posed a challenge for "educators and technology developers" that they should find ways and pedagogical strategies to implement and utilize mobile learning in education. The devices owned by learners in the form of cell phones, personal tablets, video and audio players, and smart tablets are available in every shape and to every consumer, the thing that made learners in educational institutes have access to information and facilitation on an hourly basis. This situation has created an environment in which the teacher and education designers need to calculate and plan for more effective ways to meet the fast moving evolution of this technology. Authors still find it difficult to accept an educational world that lacks pedagogical utilization of mobile and smart tablets in the fields of teaching and learning. Herrington and Herrington (2007) warned that lack the theoretical foundation for integrating this magic technology in education can lead to a wide gap between the willing of new generation learners and the ability of education institutions to adapt to trends and changes (Herrington and Herrington, 2007).

\subsection{Students, Faculty, and Scholars' Viewpoints of Employing Tablets in Education}

Seeking learner's point of view on learning to employ mobile smartphones by focus groups, Gikas, and Grants (2013) reveals the consolidation of what other scholars found regarding the profits of implementing tablets in teaching. It was useful to exploit this research when deliberating the use of tablets since the same structures are found in both tablets and smartphones. The partakers of Gikas and Grants investigation molded the profits of using tablets into four subjects: (a) fast availability of material, (b) material and social collaboration (c) abundant methods to study, and (d) positioned schooling. Regarding the last focus, positioned schooling presumes that education transpires in a similar environment in which it is purposeful, typically on an actual globe setting (Gikas \& Grants, 2013). Consequently, the prime goal of this type of learning is to connect knowledge and competences to real life instances.

The majority of researchers analyzed the application of tablets in the learning, and teaching fraternity was evaluating the learners utilize and the influence of the technology on their education and actions. It is useful to examine the faculty opinions as well as to advance grander strategy and integration of tablets in education.

Koile and Singer (2006) conducted a pilot study in which they investigated a tablet-PC-based system of assessment to enhance instructor-student interaction in large classes. They observed and analyzed the students focus and attentiveness while learning in large classes, the teacher, and student receiving of feedback, and the teacher's adjustment of materials depending on the immediate direction and information that the tablet devices provide to the instructors of large classes. As soon as the researchers introduced the tablet in combination with the Classroom Presenter software, and although the teaching style was the same, the students showed highly integrating attitudes by submitting their answers on digital devices, engaging in classroom discussion, and scoring grades that are three times 
higher than expected (Koile and Singer 2006).

Cochrane (2010) compared three Web 2.0 projects of integrating mobile technology into learning environments and found that the success of integrating technology lies in some significant factors such as pedagogical (teacher strategies) modeling of the instructional tools, "formative feedback", and careful choice of mobile devices. He stated that tasks were aimed at exploring the prospect of mobile Web 2.0 tools to improve both the official and casual instruction and studying settings with emphasis on mobile blogging.

Cochrane's recommendation was that the key to m-learning sustainability is the development of an institutional, cultural and strategy shift that supports and facilitates a lecturer. Cochrane also emphasized the fact that students need a lot of time to internalize the skills which they need for benefiting from this newly emerging technology (Web 2.0 tools) although he noticed that many students already in use of mobile devices using individual attempts (Cochrane, 2010).

\subsection{The Future of Educating Using Mobile Device Technologies}

Research to date indicates that the fast-moving dramatic change in the features of learning aggravates many difficulties for both educators and learners. For instance, senior education faces numerous challenges to endorse suitable knowledge along with reasonably priced virtual and physical digital devices. The expense characterizes the initial problem in adopting any innovative technology for on an inordinate number of learners and teachers such as in university circumstances. The expenditures of applying an innovative technology include not only the real budgets of the tools but also capacity building and indemnities anticipation costs. While the expenditures can be a burden to the application of novel practical utilization of tablets, it does not stand for the primary difficulty in learning. The chief difficulty is shaped by the readiness of both the teachers and the students to engage a new digital tool successfully. Each generation has a diverse description of success and achievement of integrating technology, so the future is certainly different from the present. Educators who have no problems with the use of technology may not be similar to the mobile education that represents a section of their student's age group technology and not their age group. Furthermore, learner's technology information might vary as compared to what is anticipated of them to recognize. This delineation between educators and learners digital knowledge signifies a struggle when development the using tablets in teaching schoolrooms and courses. Concerning these difficulties and benefits of tablet application in learning, learners and educators expressed their standpoints.

Alzaza and Yaakub, (2011) At the end of their study they emphasized that further studies and investigations should be made to discover further the efficiency of mobile technology, and devices use in higher education in general. Furthermore, the outcomes of their research exhibited that pupils have satisfactory knowledge and good responsiveness to the use such technology in their learning setting, which will impose further responsibilities on the shoulders of their instructors and their institutions. For example, Alzaza and Yaakub, (2011) indicated that the students would like their institutions to let them use for checking the exam result and course registration" (p. 95). Additionally, Alzaza and Yaakub, (2011) recommended that future studies should be shepherded with more respondents to guarantee the representative and definite conclusions.

The present patterns in mobile technology, and computing is in the line of devices that are even further entrenched, ever-present and interconnected than those accessible in the present day. The abilities of mobile devices, PDAs, cameras, and games comforts will possibly amalgamate within the subsequent five to ten years to supply a systematized, multimedia apparatus that is at all times with the user (Johnson, Brown \& Becker, 2013). Incorporated context-aware capacities will change everyday behaviors by supplying the aptitude to capture facts concerning the location, time, and persons within, and also the weather conditions. The tools of Internet and similar technological systems will develop to become both individual and movable.

Such systems can have a tremendous influence on education. Teaching will move more away from the schoolroom setting and into the learner's environs, both physical and simulated. Schooling will entail making rich associations within these surroundings to both possessions and other persons. On top of conferring with internet-founded capital on the shift, students will have the ability to control the management of their education through conferences with their individual accounts and organization-based virtual learning surroundings. The capability to immediately bring out their annotations and expressions as a digital platform will authorize them to be researchers. Context-conscious appliances will facilitate learners to capture directly, and document occasions in their existence to both help later remember and share their knowledge for mutual reflection (Johnson, Brown \& Becker, 2013). Chances for disseminated association and mobile group operation will significantly improve.

According to Bitner and Bitner (2002), teachers and educational scholars constantly cite the schoolroom teacher as 
essential to the full incorporation of technology in schools. Educators and their institutions usually make decisions about the integration of technology into the classroom. These people ought to share their ideas and concerns with their instructors to maintain their participation in the process and their understanding of the situation. Bitner and Bitner (2002) stressed the importance of inviting teachers to participate in every step toward assisting the educators through the tough change procedure essential to use and assimilate technology into the syllabus (p. 100).

The difficulty for the teachers and technology architects of the prospect will be able to discover avenues to make sure that this innovative education is extremely positioned, individual, joint and extensive term; in other terms, really student-centered education. Instructors will require adapting from a position as transmitters of information to guiders of education resources. Technology builders will want to react to issues of safety and confidentiality while planning devices and packages that students both desire and will compensate.

According to Cochrane, (2010), the prospect for mobile learning to link pedagogically planned learning settings, enable learner-generated situations, and content while offering personalized and universal shared associations, sets it from the traditional education settings. This leads us to imagine that in the future there is a lot to be done to enhance mobile learning; especially because it is a fast moving domain.

\section{Conclusion}

Most academics studying the implementation of tablets in educating did not demonstrate a development of students learning dimensions. However, studies revealed that the implementation of tablets can motivate learners to pay attention mostly to the theme. The employ of mobile tools in general help in developing student-based learning surroundings, where learners are accountable to carry on with their learning out of the classroom perimeters. Such an exercise would improve lifelong education capabilities also to the 21 st-century proficiencies (Johnson, Brown \& Becker, 2013). Universally, tablets help learners to discover, influence, and examine existing knowledge also to interact with their fellow learners and educators everywhere across the globe. Also, it is worth to note that the application of mobile apps on tablets offer an opportunity to have individualized and authentic schooling that takes care of each learner's necessity and mode. Most institution nowadays launches their device apps where the learners can access the institution knowledge and carry out their procedure quickly and from any locality. Such a move draws a representation concerning the close prospect of applying tablets in the learning and teaching platforms. It is anticipated for this rising technology to go on developing between both faculties and learners to develop more appropriate learning surroundings that meet the requirements of the novel generation schooling and nature of existence. The application of the concept of technologies in education will only advance because of the ever evolving nature of technologies. The globe is turning digital, and so will be the education sector so as to keep the face of the ever-changing contemporary world. That implies it will come to a point in time when students will no longer attend classroom lessons; rather they will attend their schedule from any position across the globe. That is the nature of the prospect technology of mobile devices and their application in learning in the prospect world. Students will only become the managers of their schooling, and they will control their time and learning sessions to fit the desires and requirements.

\section{References}

Abu-Al-Aish, A. (2014). Toward Mobile Learning Deployment in Higher Education. Doctoral Dissertation submitted to Brunel University, London.

Alzaza, N. S., \& Yaakub, A. R. (2011). Students' Awareness and Requirements of Mobile Learning Services in the Higher Education Environment. American Journal of Economics and Business Administration, 3(1), 95-100. http://dx.doi.org/10.3844/ajebasp.2011.95.100

Cheung, W. S., \& Hew, K. F. (2009). A Review of Research Methodologies Used in Studies on Mobile Handheld Devices in K-12 and Higher Education Settings. Australasian Journal of Educational Technology, 25(2), 153-183. http://dx.doi.org/10.14742/ajet.1148

Cochrane, T. D. (2010). Exploring Mobile Learning Success Factors. LT-J, Research in Learning Technology, 18(2), 133-148. http://dx.doi.org/10.1080/09687769.2010.494718

Corbeil, J., \& Valdes-Corbeil, M. (2007). Are you ready for mobile learning? Educause Quarterly, 2, 51-58.

Gikas, J., \& Grant, M. M. (2013). Mobile computing devices in higher education: Student perspectives on learning with cellphones, smartphone's \& social media. Internet \& Higher Education, 19, 18-26. http://dx.doi.org/10.1016/j.iheduc.2013.06.002 
Herrington, A., \& Herrington, J. (2007). Authentic Mobile Learning in Higher Education. In Proc. of: AARE 2007 International Educational Research Conference, 28 November 2007, Fremantle, Western Australia.

Johnson, L., Brown, M., \& Becker, S. (2013). The NMC Horizon Report. In: 2013 Higher Education Edition. Austin, Texas: The New Media Consortium.

Koile, K., \& Singer, D. (2006, April). Development of a tablet-pc-based system to increase instructor-student classroom interactions and student learning. In Proc. of: Workshop on the Impact of Pen-Based Technology on Education (WIPTE'06).

Nassoura, A. B. (2012). Students Acceptance of Mobile Learning for Higher Education in Saudi Arabia. International Journal of Learning Management Systems, 1(1), 1-9. http://dx.doi.org/10.12785/ijlms/010101

Ruiz, J. G., Mintzer, M. J., \& Leipzig, R. M. (2006). The Impact of E-learning in Medical Education. Academic Medicine, 81(3), 207-212. http://dx.doi.org/10.1097/00001888-200603000-00002

Schnackenberg, H. (2013). Tablet Technologies and Education. International Journal of Education and Practice, 1(4), 44-50.

Sha, L. L., Looi, C. K., Chen, W. W., \& Zhang, B. H. (2012). Understanding Learning from the Perspective of Self-regulated Learning. Journal of Computer-Assisted Learning, 28(4), 366-378. http://dx.doi.org/10.1111/j.1365-2729.2011.00461.x

Wang, M., Shen, R., Novak, D., \& Pan, X. (2009). The impact of mobile learning on students' learning behaviors and performance: Report from a large blended classroom. British Journal of Educational Technology, 40(4), 673-695. http://dx.doi.org/10.1111/j.1467-8535.2008.00846.x 